\title{
К ВОПРОСУ ОБ ИСПРАВЛЕНИИ ОШИБОК НА ЗАНЯТИЯХ АНГЛИЙСКОГО ЯЗЫКА
}

\section{THE ISSUE OF CORRECTING MISTAKES IN CLASSES OF ENGLISH}

\section{T. Golikova}

Summary: The article focuses on ways of correcting mistakes typical of different schools of methods of teaching. An attempt is made to outline the strategy of a lesson with an optimal ratio of error correction and communication.

Keywords: error correction, selective error analysis, delayed error analysis, grammar skill, lexical skill.
K аждый преподаватель иностранного языка сталкивается с вопросом: как исправлять грамматические, лексические, фонетические ошибки студентов, но при этом не нарушать их речь? Не вызывает сомнения, что делать это надо, но как это делать корректно по отношению к студентам, в том числе к студентам разного уровня языковой подготовки? Ответ на данный вопрос и составляет цель этой статьи.

Двадцатипятилетний опыт преподавательской работы и обмен опытом с коллегами-профессионалами показывает, что есть два подхода к исправлению ошибок.

Первый характерен для преподавателей старой, классической школы. Преподаватели старой школы считают, что абсолютно все ошибки должны исправляться. Они также придерживаются точки зрения, что отличную оценку студенту можно поставить только в том случае, если в ответе нет ни одной ошибки (только если студент сам исправился).

Другой подход характерен для более передовых (с нашей точки зрения) преподавателей. Он состоит в том, что ошибки нужно исправлять не все, а только наиболее характерные. Например, если сильный студент пропустил артикль или окончание -s в речи, эту ошибку можно не исправлять. Это оговорка, потому что студент знает правило. Исправлять нужно ошибки на новый или сложный материал, который пока еще не усвоен (например, Complex object, согласование времен, времена в условных предложениях). Такие ошибки обычно делают речь непонятной, а коммуникацию невозможной.

Второй подход поддерживают и иностранные методисты: Дж. Уолз и Дж. Хендриксон. Они считают, что при
Голикова Татьяна Олеговна

К.филол.н., дочент, Российская академия народного хозяйства и государственной службы при Президенте

Российской Федерации, г. Москва tatianagolikova73@yandex.ru

Аннотация: В статье анализируются подходы к исправлению ошибок, характерные для методистов разных школ. Также делается попытка наметить стратегию урока с оптимальным соотношением исправления ошибок и коммуникативной деятельности.

Ключевые слова: исправление ошибок, выборочный анализ ошибок, отсроченный анализ ошибок, грамматический навык, лексический навык.

обучении говорению нужно стимулировать студентов высказывать свое мнение, и для этого меньше исправлять. В зарубежной методике такой подход получил название selective grammar analysis [2. c.8, 28].

Рассмотрим достоинства и недостатки двух подходов. Рассматривать их мы будем на материале коммуникативно-направленных упражнений. «В упражнениях с коммуникативной направленностью рекомендуется отсроченный анализ ошибок [1. с.97]». Иными словами: студент должен сначала закончить мысль, а потом преподаватель просит его повторить предложения, где он ошибся. Тогда преподаватель объясняет ошибку.

Начнем с полного анализа ошибок. В сильных, мотивированных, прекрасно работающих группах такая работа идет очень хорошо. Студенты активно учатся, начинают понимать свои ошибки и дают об этом сигнал преподавателю ("I have got it"). Полный отсроченный анализ ошибок не только не замедляет урок, но и движет его вперед, делает более интенсивным. Преподаватель может полностью или частично протоколировать ошибки, чтобы ничего не забыть. На высоких уровнях хорошо идет также взаимное исправление ошибок: студенты сами записывают ошибки своих коллег, а затем просят повторить предложение и исправляют их. В основном ошибки этих уровней - это косвенный вопрос, двойное подлежащее (Mr. Brown he went for a walk), перескок с одного времени на другое, а также лексические, фонетические ошибки.

Иную картину мы видим в группах среднего уровня. Как показывает практика преподавания, многие студенты уровня Intermediate делают много ошибок. Это и постоянные пропуски артиклей и третьего лица един- 
ственного числа, неправильное образование прошедшего времени, полное отсутствие Past Perfect и Complex object, лексические ошибки.

Поэтому, когда студент отвечает и произносит даже небольшую реплику, у преподавателя накапливается длинный список ошибок. Если после каждой реплики (и даже в конце дискуссии) комментировать и исправлять все ошибки, то студенты уже забывают, что они хотели сказать, и дискуссия разваливается. Диалог преподавателя и студента на тему урока превращается в монолог преподавателя об ошибках. При этом, на занятии теряется атмосфера живого общения со студентами, и возникает тяжелая атмосфера и скука.

Таким образом, достоинство полного анализа ошибок - это интенсивная работа над грамматикой. А недостатком его в слабых и средних, и даже сильных группах являются потеря коммуникативности, и, как следствие, потеря мотивации студентов к учению. Это очень серьезно. Особенно часто потеря интереса к учению происходит в смешанных группах уровня Intermediate, где часть студентов - сильные, а часть - слабые. Сильные студенты устают слушать одни и те же прописные истины и перестают посещать занятия.

В случае с selective grammar analysis такого не происходит. В сильных и слабых группах преподаватель комментирует лишь важнейшие грамматические ошибки, мешающие коммуникации. Речь студентов при этом не нарушается, и урок проходит интересно, в коммуникативной атмосфере.

Единственным недостатком selective grammar analysis является то, что не исправляются и теряются многие базовые грамматические явления. С недостаточно чистой речью студенты приходят на следующий урок, и дальше, на зачет или экзамен. Также грамматические ошибки, если их не исправлять, «прилипают» к другим студентам, засоряют и их речь. Но это не самая большая проблема.

Самая большая проблема - это то, что показывает мировая практика. Солидные научные журналы заворачивают статью, если она написана неграмотно. Вот почему при обучении иностранному языку должен проводиться анализ и коррекция ошибок, особенно не профильном уровне.

Так как же совместить достоинства двух подходов и минимизировать недостатки?

Во-первых, думается, очень многое зависит от преподавателя. Если преподаватель создаст в группе учебный коллектив, в котором каждый будет знать свои ошибки и стремиться от них избавиться, то любой анализ ошибокполный или выборочный - будет проходить хорошо.
Во-вторых, преподаватель должен учить студентов не торопиться, внутренне проговаривать свои высказывания и следить за своей речью (to monitor one's speech).

В-третьих, и это, наверное, самое главное, преподаватель должен ориентироваться на сильных студентов, которые поведут за собой всю группу. Их грамматические и другие ошибки нужно исправлять в первую очередь. А слабым студентам нужно давать карточки, дополнительный материал на их ошибки. Также задания на ошибки слабых студентов нужно включать в проверочные работы. К ошибкам на базовую грамматику можно и нужно возвращаться на новом уровне (на новом лексическом материале, при обсуждении новых тем, в проверочных работах).

В-четвертых, как справедливо утверждает Н.С. Харламова, помимо простого исправления ошибки есть множество способов указать на нее студенту. Вот ее перечень приемов для исправления ошибок в устной речи:

«- указать на наличие ошибки;

- перефразировать вопрос;

- попросить дать объяснение ключевых выражений;

- уточнить вопрос

- обозначить грамматическую область ошибки;

- привлечь внимание с помощью жестов.» [1. с.97-98].

В письменной речи это:

«- ссылка на конкретный материал, необходимый для понимания существенного явления;

- заметки на полях» [См. там же].

Автор данной статьи считает, что любой из этих примеров предпочтительнее простого исправления неправильного варианта на правильный. Эти варианты исправления ошибок не прямолинейны, они разряжают обстановку, если атмосфера на уроке очень тяжелая. Это корректные, тонкие, умные приемы, которые дают возможность студенту самому найти правильный ответ.

И наконец, последнее по счету, а не по важности, анализ ошибок в речи должен быть отсроченным [1. с.97]. Студент сначала должен закончить мысль, а потом преподаватель должен вернуться к предложениям, где студент ошибся, и выявить, объяснить ошибку.

Очень хорошей практикой является взаимный анализ ошибок студентами группы. Перед ответом студента преподаватель дает установку на фиксирование ошибок: "The others should write down mistakes if any". После ответа студента он обращается к группе "Any mistakes noticed?"

Очень хорошо, когда студенты исправляют ошибки друг друга и без указания преподавателя. Этому ни в коем случае не надо препятствовать, а напротив, надо 
поощрять.

В целом исправление ошибок - очень важный элемент занятия английского языка.

Но проводить его надо корректно, творчески, и, не побоюсь этого слова, интересно, так, чтобы максималь- но легко и доступно донести до студента правильный вариант. Какой способ исправления ошибок выбрать - зависит от группы, преподавателя: его методики и личного опыта. При этом, если способ выбран правильно, это дает преподавателю возможность совместить коммуникативную направленность занятия с активным формированием грамматического и лексического навыка.

\section{ЛИТЕРАТУРА}

1. Харламова Н.С. Анализ ошибок в устной и письменной речи, способы их исправления //МГЛУ: «Языковая относительность: английский лексикон и текст»/сб. н. тр. № 441 - М., 1998. - С.96-100.

2. J.D. Wolz. Error Correction Techniques for the EPL Classroom. - Chicago: Chicago Centre for Applied Linguistics, 1982. - 40 p.

3. S.P. Corder. Error Analysis and Interlanguage. - Oxford: Oxford University Press, 1981. - $119 \mathrm{p}$.

4. Language Teaching and Linguistics: Surveys. - Cambridge: Cambridge University Press, 1982. - 199 p.

(с) Голикова Татьяна Олеговна (tatianagolikova73@yandex.ru).

Журнал «Современная наука: актуальные проблемы теории и практики»

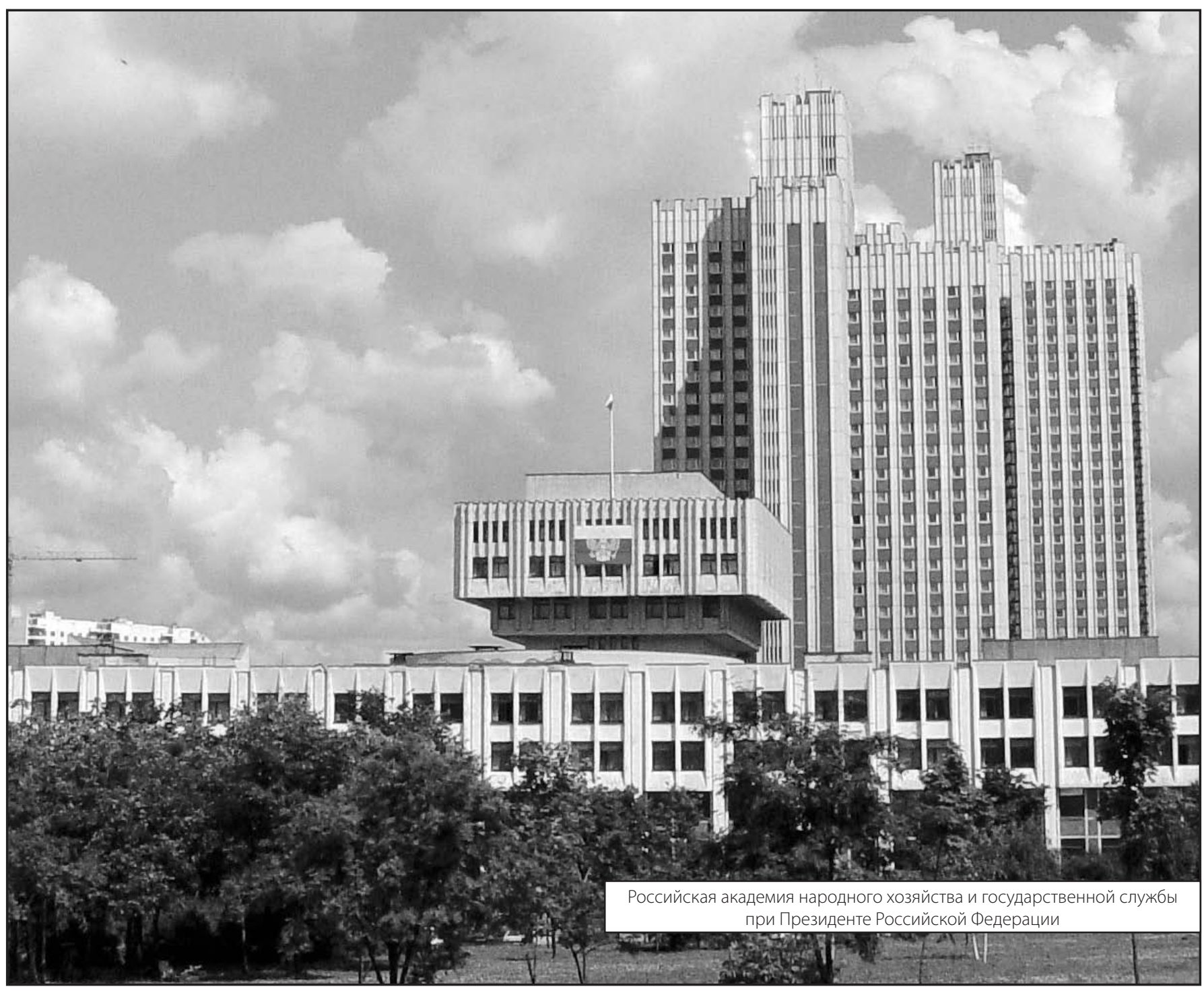

